\title{
CORPO-TERRITÓRIO COMO ARGUMENTO CURRICULAR DE RESISTÊNCIA
}

\author{
Ana Angelita da Rocha ${ }^{1}$
}

\section{INTRODUÇÃO}

Eu não sei como conseguia correr, menó, papo reto, meu corpo todo parecia que tava todo duro, tá ligado? Geral na rua me olhando. Virei a cara pra ver se ainda tava na mira do verme, mas ele já tinha dado as costas pra continuar revistando os menó. Passei batido!

Rolézim, Geovani Martins, 2018, p. 16.

A escrita jovem periférica, negra e rebelde está nos muros, nas rádios, na novela das oito ou no jornal das elites, como a prosa consagrada editorialmente de Geovani Martins. Marginalizada ou invisibilizada, a juventude pobre, global ou localmente, terrritoriza-se demandando suas aspirações e angústias, como na passagem de Martins. A escrita do espaço vivido tem sido igualmente requisitada nas escolas? É possível falar das insurgências das ocupações sem vislumbrar como esses jovens vivem e apropriam-se do espaço da cidade? Se moradores do campo, como se dá a relação com a terra?

Essas perguntas se desdobram da crônica de Martins porque "passar batido", por muitas vezes, é sobreviver na precariedade (BUTLER, 2017). Não tenho a pretensão de esgotar tais interrogações provocadas pela crônica, mas sou afetada por suas angústias. Este trabalho resulta da inquietação provocada por minha pesquisa de pós-doutoramento, pela minha experiência com a formação de professores e como professora de Geografia. Seu propósito é tratar as incursões pedagógicas e estéticas como experimentação para significar a relação corpo-território. Em outras palavras, no império da necropolítica, me parece urgente que haja percepções de currículo que se engajem no argumento corpo-território, como nos ensina Hernández (2016).

Assim como os quilombolas, indígenas e expropriados do campo, a provocação de rolézim de Martins dialoga com a significação espacial desses jovens que, no entender de Butler (op. cit.), experenciam a vida precária. E o "viver na mira" coisifica os corpos lembrados pela necropolítica de Achile Mbembe (2014), ao afirmar as marcas da colonização dos povos; e pelas ecofeministas, que,

\footnotetext{
${ }^{1}$ Possui graduação em Geografia pela Universidade do Estado do Rio de Janeiro (2004) e mestrado e doutorado em Educação pela Universidade Federal do Rio de Janeiro (2008, 2013). Atualmente é professora (Adjunto III) do Departamento de Didática da Faculdade de Educação na Universidade Federal do Rio de Janeiro
} 
ao alertarem que o petróleo deve ficar abaixo do solo amazônico, apresentam novos paradigmas para interpretar a relação sociedade e natureza. São, portanto, múltiplas as geografias dos rolézim.

Este texto tem como propósito principal narrar as minhas lembranças docentes, com foco na concepção corpo-território como um dispositivo curricular que se alicerça numa interpretação política e estética. Assim, essa argumentação é desenvolvida em duas seções. Na primeira, Corpo-território como argumento potente, procuro tecer alguns diálogos provocados pelas geografias feministas que poderiam sinalizar percepções passíveis de conversas com a reflexão curricular. Na última, Lembranças corpo-território de uma professora, focarei na concepção corpo-território a partir da discussão de geopolítica do útero para a reflexão curricular, considerando a minha experiência como professora da rede pública.

Os movimentos ecofeministas na América Latina vêm ensinando que toda estratégia de resistência é sempre territorial e envolve nossos corpos. De modo que tais movimentos de mulheres indígenas argumentam que a cada resistência há, todavia, uma reação masculinizada do espaço, que violenta (de distintas formas) as comunidades e seus corpos. Os movimentos ecofeministas alertam sobre a relação racial e patriarcal do neoliberalismo. Essas aproximações conceituais introduzem aprendizagens outras em que se procura compreender a relação corpo-território, o que significa fazerse corpo sensível, biológico, simbólico determinado e determinando território. Então, o agir-falar-ser da periferia mobiliza ou se imobiliza no espaço. Em outras palavras, o onde ser desses corpos está nos desejos ou nas frustações das nossas escritas docentes.

\section{CORPO -TERRITÓRIO COMO ARGUMENTO POTENTE}

Neste sentido, o ecofeminismo nos permite ver as relações de subordinação estabelecidas por uma cultura patriarcal que tem inferiorizado a Natureza e naturalizado o feminino para estabelecer processos de apropriação ou de controle dos corpos e dos territórios para o desenvolvimento do capitalismo. Uma cultura que na origem se apresenta desde uma lógica masculina, branca, burguesa, de espaços de poder económico e político donde se decide sobre os territórios de comunidades inteiras, de natureza pouco alterada ou de sociedades com outras lógicas de vida. Colectivo Miradas Críticas del Territorio desde el Feminismo, Equador, 2013, s/n, grifos nossos.

O fragmento acima, extraído do Manifesto das ecofeministas equatorianas, anuncia que o modelo vigente ameaça nossos corpos e nossos territórios. Recentemente, em agosto de 2019, reuniram-se, em Brasília, cerca de duas mil mulheres indígenas, cujo Manifesto "Território: nosso 
corpo, nosso espírito" denunciava e demandava o direito ao atendimento diferenciado à saúde e à educação. Elas, de fato, revelam a indissociabilidade do corpo-território à agenda de luta.

Reafirmamos o nosso compromisso de continuar a luta em defesa dos nossos territórios, de nossos conhecimentos e saberes tradicionais, das políticas específicas e diferenciadas, especialmente nas áreas da saúde e da educação. Reafirmamos, ainda, o pacto entre nós mulheres indígenas de todo o Brasil que não vamos nos calar, não vamos recuar e não vamos desistir de lutar pela vida e o nosso futuro. Seguimos em MARCHA... Território: nosso corpo, nosso espírito! (Brasília DF. 12 de agosto de 2019. Articulação dos Povos Indígenas do Brasil - APIB)

Se aprendermos com os movimentos das mulheres indígenas latino-americanas, entenderemos a potência do corpo-território como argumento de nossas pautas. Aqui entra em questão a dimensão material e imaterial do espaço-tempo no currículo. Inspirado numa esperança de outro olhar sobre o território, nosso exercício é reinventar ou reforçar uma proposta curricular em torno do argumento corpo-território. Considerando, sobretudo, que o ofício docente é ocupado por mulheres e, em particular, que a emergência das políticas neoliberais de responsabilização violenta os corpos pela precarização (VALVERDE: 2015, p. 22), é conveniente reposicionar essa mirada para proposições curriculares resistentes.

Quando Hernández (2016: 37) define o corpo-território como argumento de luta dos coletivos feministas indígenas na América Latina, ela faz referência às centenas de coletivos cuja pauta “ $m i$ cuerpo, mi território" se desloca para a saúde dos corpos e a consciência do território. De igual forma, Hernández nos lembra que as lutas atravessam séculos de genocídios, em que a violação dos corpos das mulheres é ferramenta política. Nossos currículos poderiam ser provocados por tal aporia? Quando pensamos em currículo, nossas conversas deslocam para o centro a ideia de corpo-território? Pensar nas violências sobre os corpos que se (re)territorizam nas escolas é uma atribuição curricular?

Ao fazer tais questões, reconheço que diferentes teorizações curriculares fundamentam seus problemas na definição de subjetividade. Há, portanto, o que seria uma longa tradição do campo em perscrutar as premissas sobre subjetividade no exercício da definição de currículo. A proposição aqui não é diferente, mas é oferecida indagando se o pensamento sobre/com o currículo nos inclina a inventariar como qualificamos a relação corpo-território nas nossas reflexões. Para tanto, parece conveniente a aprendizagem com Hernández, para quem é urgente reposicionar a mirada política. Diz a autora:

Neste argumento, o corpo é visto como território em si mesmo num espaço, um território, um lugar, que ocupa, ademais, um espaço no mundo e pode vivenciar todas 
as emoções, sensações e reações físicas para encontrar nele um lugar de "resistência" e ressignificação (2016:42, tradução livre).

Isso implica acompanhar os debates sobre territórios de resistência, uma vez que não somente a escola, mas outras instituições ligadas ao conhecimento são confrontadas por pautas racistas, misóginas e profundamente anti-intelectualistas. Tal exercício é tributário desse tempo-espaço. Então, não é acidental que a premissa (corpo-território como argumento) migre dos coletivos subalternizados, especialmente das mulheres indígenas latino-americanas, para se pensar uma ética e uma estética de resistência quando se quer falar de currículo, o que significa que há constantemente o reposicionamento da forma como se concebe a relação entre a subjetividade e a produção do conhecimento.

Com efeito, convém dialogar com as reflexões feministas de Doreen Massey (2004), quando ela resgata, em geografias da responsividade, um compromisso ético no tripé político espaço-sabersubjetividade. Em resumo, a autora oferece a concepção dos lugares de encontro como uma estratégia política. Assim como Massey, Linda McDowell (2019) inscreveu o corpo da mulher no espaço, pois para as precursoras das geografias feministas é inviável separar o corpo do espaço, num projeto crítico. Em outras palavras, o interesse das geógrafas pelo corpo denuncia a estrutura patriarcal inscrita nas funções do espaço. Portanto, como concluiu Hernandez (2016: 41), todo corpo está inscrito numa geografia de poder.

Aliás, Massey $(2004,2008)$ denunciou por diversas vezes as implicações políticas quando há a recusa de uma concepção mais complexa do espaço. A ideia de representação do espaço apartado do tempo e da política impede a percepção das geometrias de poder. Com isso, é possível ter uma chave de interpretação cara para esse exercício: não basta negar ao currículo a concepção do espaço. Não se trata exclusivamente da adjetivação escalar, ora currículo nacional, ora local, por exemplo.

Ao se defender uma proposição que parta da indissociabilidade corpo-território para significar o currículo, parte-se também de um compromisso ético e estético de pensá-lo não mais como uma localização superficial. Ao contrário, tal empreitada requer que a concepção do espaço esteja provocada nos movimentos de proposição e operacionalização curricular. Afinal, a razão corpoterritório é tributária de diferentes hierarquias, como questiona Oliveira, ao tratar da cidade como lugar racializado (2017:79).

A cidade deixa de ser o lugar do abrigo e passa a ser o lócus do medo e do perigo racializado. As estratégias de segregação são postas como bem-vindas para afastar o mal-estar e gerar uma sensação de segurança (OLIVEIRA, 2017: 79). 
Em uma palavra, o horror! O infanticídio, em última análise, produzido por uma operação militar em horário e no entorno escolar contraria qualquer contrato social ou protocolo de Guerra. Em 20 de junho de 2018, Marcos Vinicius tinha 14 anos, quando foi assassinado a caminho da escola, durante uma operação policial com o uso de helicópteros. ONGs e moradores da Maré contaram cerca de cem projéteis perto das escolas ${ }^{2}$. Marcos Vinícius, assim como outras crianças na franja metropolitana do Rio de Janeiro, morreram vítimas da necropolítica. Em outras palavras, uma política racializada em que o algoz e a vítima estão, no entender de Zaragocín (2018), numa relação intricada entre corpo-território-morte. Afinal, as crianças morreram em territórios onde seus corpos eram vulneráveis à lógica de extermínio.

Em 2018, Zaragocín descreveu a colonialidade dos colonos ${ }^{3}$, em que se acentua a geografia racializada pela supremacia branca (2018:2). Pela dinâmica do medo e do horror, as crianças mortas são narradas e sentidas nos currículos de resistência. Diante da profusão de territórios contidos e interditados, como lembra Oliveira (2017), é preciso falar do luto dos corpos mortos. Porque certamente a morte de um colega ou de um aluno fere a escola. Então, a relação corpo-territóriomorte significa as práticas cotidianas na escola.

Tanto as ecofeministas indígenas quanto as comunidades escolares da Maré produzem política de conhecimento ao reivindicarem a indissociabilidade entre corpo e território. Claro que as motivações e as estratégias de comunicar a agenda política são profundamente distintas porque os territórios e corpos são distintos. O ensaio de tentar ver a relação corpo-território como relação curricular é inscrever ou sublinhar outras formas para reinventar a profissão e a formação docente, nos rastros de uma era de negacionismos científicos e aprofundamento da censura, como projetos do “Escola sem partido". Por isso que o convite de pensar a relação corpo-território como argumento curricular, incorporando linguagem e estética, parece ser uma via de repensar o espaço, mais

\footnotetext{
2 Disponível em: https://noticias.uol.com.br/cotidiano/ultimas-noticias/2019/06/20/1-ano-da-morte-na-mare-muitosmarcos-vinicius-morrem-a-cada-dia-diz-mae.htm Acesso em agosto de 2019.

3 La colonialidad de colonos se manifiesta mediante la eliminación étnica dependiente del lugar, a menudo solidificando el patriarcado heterosexual donde el espacio cotidiano se convierte en un lugar de control y de vigilancia colonial (Denetdale, 2017), convirtiéndose en un proyecto centralmente racializado y sexualizado (Baker, 2017; Goeman, 2013; Goeman, 2017). La eliminación de una etnia atraviesa necesariamente a los cuerpos de mujeres racializadas debido a su capacidad de reproducción y de su rol para la continuación de la vida (Smith, 2015). La relación entre mujeres racializadas y reproducción espacial en contextos de eliminación étnica, tiene necesariamente que ver con su rol en la continuidad de vida10, y a su vez, con su implicación en procesos de muerte-cuerpo-tierra. La lógica de eliminación étnica pasa por los cuerpos de mujeres indígenas, justamente porque es desde sus funciones reproductivas desde donde se puede enfrentar a la estructura colonial que tiene como finalidad, su muerte colectiva. (ZARAGOCÍN, 2018:7).
} 
precisamente reinventar as escolas - e em particular os currículos - como "lugares de encontro" (MASSEY, 2008).

Inspirada em Achile Mbembe (2014), é possível imaginar que um currículo resistente seria aquele que insiste num propósito de descolonização. Um currículo em carne viva que se determina em relação ao futuro. Ou, tomando de empréstimo do filósofo camaronês, pode-se pensar num currículo como "uma experiência de uma nova forma de vida e uma nova relação com a humanidade" (MBEMBE, 2014: 22).

Afinal, não bastaria descolonizar, seria preciso ainda uma autodescolonização, uma ruptura com uma pretensa universalidade abstrata e alheia ao sofrimento dos corpos vulneráveis. Dito de outra forma, um currículo resistente a partir do corpo-território requer inventar a escola como lugar de encontro dos diversos vulneráveis e maestros de uma autodescolonização, pois o currículo de resistência interroga os processos colonizadores de saberes e, mesmo sendo a escola um lugar de passagem dos alunos e das alunas, ela merece ser um lugar de encontro que potencialize esses corpos e suas territorialidades.

Nestas primeiras páginas do texto, busquei, a partir das geografias e lutas feministas, aprender com Hernandez (2016) a potência do corpo-território como argumento. E, como argumento, a relação (não binária) corpo-território não reivindica um fim em si mesma. Quer dizer que a enunciação corpoterritório não abrigaria exclusivamente uma única epistemologia ou escala.

No corpo que luta, há múltiplos territórios, territorialidades e escalas. O corpo da mulher - que luta contra a vulnerabilidade à violência - abriga muitas esperanças. Não é por acaso que Hernandez (2016: 44) sublinha a potência do argumento, recordando que ele é produzido no seio comunitário, na vida em comunidade dessas mulheres latino-americanas que rechaçam uma via de mão única para explorar a terra. Aliás, a potência do argumento corpo-território está em permitir as multiplicidades das perguntas pelas mulheres, que, por sua vez, geram aberturas políticas das pautas e das estratégias.

É interessante observar que, ao deslocar o debate do corpo-território para o centro da luta feminista e indígena, a mulher latino-americana sinaliza a abertura de um processo ativo e estratégico. Um exercício curioso é também inventariar e imaginar as tentativas de abertura da concepção curricular. Por exemplo, vale mencionar a tradição norte-americana, coetânea das lutas pelos direitos civis nos Estados Unidos nos 1960/70, o movimento da Reconceptualização, preconizado por William Pinar, que cunhava o currere como método autobiográfico, contrapondo-se à racionalidade técnica e às matrizes mais prescritivas do currículo. Convém sublinhar a estratégia de abertura das teorizações de currículo, dialogando com a análise de Miller (2014): 
Ao longo dos últimos mais de 40 anos, formas de teorização de currículo proliferaram e preencheram as investigações educacionais com subjetividades incorporadas, conflitantes e em conflito, bem como com estudos sobre que influências, eventos e interpretações psico-socio-historico-discursivo-culturais dominantes dão forma ao que é "oficialmente" construído, experimentado e "compreendido" como currículo e ensino (MILLER, 2014, P. 2048).

A abertura curricular como processo epistemológico e ativo provoca interpretações sobre o “oficialmente" concebido como currículo e ensino. A nevralgia da estratégia está em contestar a colonização de quaisquer proposições curriculares.

No que diz respeito à abertura da concepção de currículo, Miller (2014) novamente sublinha a importância de seu esgarçamento ao invés de um projeto fixo e homogêneo de currículo, como se nota nas políticas de responsabilização docente em diferentes lugares do globo.

Essas aberturas podem permitir diversas percepções do que pode significar, em contextos educacionais específicos, ensinar, aprender - de fato, prestar atenção nos aspectos simultaneamente pessoais, sociais, culturais e políticos do "entendimento do currículo". E - se desejado - eu acho que todos aqueles envolvidos em educação podem ampliar esses insights de mais de 40 anos de teorização de currículo para soltar, desafiar e talvez até quebrar as escrituras e mandatos de versões positivistas (re)correntes e técnico-racionais de currículo que sustentam medidas padronizadas de prestação de contas e conquistas (MILLER, 2014 P. 2051).

O que se nota brevemente é que há diversos grupos em diversas geografias com vontade de expandir, esgarçar, nesse sentido, a concepção de currículo. E como processo ativo, a abertura é potência. Em outras palavras, a multiplicidade da abertura curricular é um projeto de resistência para “desafiar e talvez até quebrar as escrituras" de proposições curriculares colonizadoras - por exemplo, com o projeto de conhecimento passível de ser testado - que interditam processos de subjetivação.

Se a potência do argumento corpo-território reside na abertura do espaço, é possível acolher esse aprendizado das marchas das mulheres indígenas latino-americanas para nos permitir questionar e desenhar os currículos de resistência que sejam traçados na multiplicidade e na esperança da vida comunitária.

Essa proposta de abrir e desafiar a concepção de currículo é uma questão constante no campo, que vem ao longo de décadas se antagonizando com a prescrição e a racionalidade técnica de uma visão da administração escolar. De acordo com Gabriel (2015), no fazer curricular a aposta numa leitura política determina a postura epistêmica que "desautoriza a falar no lugar do outro, exigindo 
problematizar, questionar determinados quadros de inteligibilidade que pretendem traçar previamente e de maneira engessada o caminho da luta e da resistência à ordem social desigualmente estruturada na qual nos movemos." (2015: 426).

Essa discussão repercute no entendimento do corpo-território nas escolas. No que diz respeito a tais relações, cabe dialogar com a seguinte provocação: “O corpo modela o espaço ou o espaço modela os corpos?" (ACARÓN, 2016: 140, tradução livre). Para a coreógrafa, o corpo modela o espaço e o espaço modela os corpos, como o rolézim, nesse caso, é sintoma e ao mesmo tempo causa das reterritorializações dos corpos jovens na cidade cindida. Aliás, como lembra a autora, o espaço é moldado pelas percepções de vulnerabilidade e de violência (ACARÓN, 2016: 146).

A provocação de Acarón aponta também para o quadro de inteligibilidade da concepção curricular partindo do espaço escolar, o que permite vislumbrar ainda que a política curricular como política de conhecimento aciona interpretações espaciais (ou imaginações geográficas) que estarão fora dos terrenos validados pelas prescrições, como a Base Nacional Comum Curricular e correlatos. Esse argumento dirige as próximas análises da última seção que buscarão refletir sobre as perspectivas curriculares alternativas ao regime estético colonizador do corpo, para, então, problematizar politicamente o debate do corpo-território e a dimensão decolonial da geopolítica do útero. Essa correlação de ideias se apoia em Zaragocín (2018), que se ocupa do impacto em que a "simultânea violência exercida ao corpo e ao espaço tem sido teorizada de maneira distinta, enfatizando ao determinante espacial da experiência e sua conceptualização" (2018: 4).

\section{LEMBRANÇAS CORPO-TERRITÓRIO DE UMA PROFESSORA}

(...) o útero cria sua própria territorialidade.

Sofía Zaragocín (2018, p.01).

a)

A citação que abre a última seção deste ensaio nos desafia a realizar uma inflexão para pensar a tríade corpo-território-currículo. Zaragocín (2018), defendendo a pauta indígena feminista, argumenta a favor de que, diante das violências que colonizam os corpos, é necessário pensar uma geopolítica4 do útero. Este ensaio exercita essa ideia ao pensá-la numa dinâmica de resistência para o fazer curricular.

\footnotetext{
4 No que diz respeito à discussão sobre a geopolítica feminista, convém a seguinte citação de Zaragocín: A geopolítica feminista, uma subdisciplina da geografia feminista, mostra as relações de força que operam mediante e sobre os corpos, fazendo que certas subjetividades e corporalidades se mantêm vulneráveis, exploradas e violadas em relação à seguridade, população, território e nacionalismo (Dixon 
Isso significa um contexto que permita indagar como pensar proposições curriculares outras para refletir essa relação com consequências de resistência. A história da tragédia genocida que vitimou Marcos Vinícius e outras crianças nas franjas metropolitanas no Rio de Janeiro deveriam e, certamente, envolvem as escolas e suas práticas cotidianas. Nessa direção, contar a história das pessoas nas escolas e sobre as escolas das pessoas é, sobretudo, pressupor que "os corpos existem nos lugares, mas as vezes são lugares" (ZARAGOCÍN, 2018, 8).

Para tanto, também nos inspiramos rasgadamente em "Sair da grande noite - ensaio sobre a África descolonizada", de Achile Mbembe (2014), em que o filósofo camaronês recorre ao registro autobiográfico para alargar a problematização do conceito de descolonização. Aqui, claramente, faço referência às minhas lembranças docentes para especular o argumento corpo-território, em especial a geopolítica do útero, para proposições curriculares outras. Com esse exercício, ofereço o registro narrado das minhas lembranças como um laboratório aberto.

Outra referência muito forte para compartilhar minhas lembranças de corpo-território de professora está em Delmy Hernández, quando a antropóloga feminista indígena confessa que seu texto é uma compartición. "A palavra compartición é uma proposta zapatista que nos diz que queremos contar de nosso ser e estar no mundo com outras pessoas" (2016: 36). Se a proposta deste texto é uma imaginação outra do currículo a partir do corpo-território, entendo-a como compartición, porque a vontade de saber inscrita noutro currículo requer a força de meu corpo. Por isso que a reinvenção curricular é contada considerando o meu corpo.

Todavia, neste ensaio não estou focada no estudo da arte sobre narrativa e currículo ou autobiografia e currículo. Há, sem dúvida, distintas correntes teórico-metodológicas que vêm se ocupando da potência dessa relação. Contudo, é possível notar que o esforço biográfico, com foco nas experiências cotidianas, tem sido uma temática para problematizar alternativas do fazer curricular.

Mesmo na era da testagem, como já reivindicou Janet Miller, citada neste ensaio, o esforço autobiográfico é um gênero de resistência, cambiando histórias possíveis que interrogam o sistema prescritivo de atuais proposições curriculares. Com efeito, amparo-me nessa autora, para quem são

\footnotetext{
Marston, 2011, pág. 455). O imaginário geopolítico feminista (Hyndman, 2001) incorpora corpos, subjetividades e corporalidades teorizando sobre eles desde a escala do cotidiano e os convertendo em lugares sobre os quais as tensões geopolíticas se impregnam de práticas socioespaciais. A relação entre as escalas de poder, através do corpo e da experiência situada, tem sido os pilares que caracterizam a geopolítica feminista anglocêntrica. É desde esta lógica que se enfatiza a escala do íntimo e no espaço-tempo da cotidianidade para entender as relações de poder dentro de espaços onde se tem analisado escassamente o poder estatal. (ZARAGOCÍN, 2018:8, tradução livre).
} 
necessárias teorizações curriculares que envolvam a abordagem autobiográfica, especialmente nos espaços-tempos curriculares de silenciamento e de censura. Ou, em suas palavras, "esforços autobiográficos de teorização de currículo podem nos permitir notar que o que contém também exclui" (2014: p. 2058).

Iniciei minha carreira como professora da educação básica na franja metropolitana, precisamente em Jardim Gramacho, Duque de Caxias, e na zona rural de Bom Jardim, no estado do Rio de Janeiro, deslocando-me em diferentes territórios de pobreza, onde corpos jovens, de jovens trabalhadores, desafiam e reinventam a vida precária. Vem-me à lembrança como a inexperiente professora planejava aulas colonizadas por uma vontade de saber que, por vezes, me geravam profunda frustação devido àquela história de que não sabia ensinar para aqueles alunos. Porque minha imaginação de boa aula não contava com aqueles alunos e alunas subalternizados num país desigual. Essa frustração encarna uma colonialidade, uma "violência lenta", porque a minha significação de boa aula prezava uma ideia curricular centrada num conteúdo "de fora" (Zaragocín, 2018, p. 8). Em outras palavras, quando projetamos uma aula colonizada, de certo desprezamos as diferentes territorialidades de saber e cotidianas presentes no pátio e nas salas de aula.

São muitas as lembranças docentes da rede pública, mas confesso que sempre tive muita dificuldade em desenvolver planejamentos ou proposições que atendessem às minhas alunas grávidas. $\mathrm{Na}$ verdade, mesmo sendo mulher, não considerava a particularidade de demandas de uma aluna grávida. Limitava-me à empatia e a justificar as faltas delas. Hoje, vejo o quanto isso era pouco. Aliás, não só eu. As escolas silenciam aqueles corpos, não há espaço de atendimento que crie prioridade ou acolhimento. As aulas são pensadas para corpos sem útero, pois as alunas e seus úteros não são convidados aos nossos projetos de escola.

Minha lembrança é de uma solidariedade intrínseca com as meninas. Certa vez uma turma me pediu para usar o tempo da aula para um chá de bebê, não resisti, pelo afeto, e “cedi” o tempo-espaço da aula para que a escola fosse convertida noutro lugar de encontro onde aquela menina e seu útero eram protagonistas e acolhidos. Geralmente, são meninas que sofrem toda sorte de violência, incluindo a da própria escola e de seus professores: a gravidez na adolescência é estigmatizada.

Para mim, essa lembrança me obriga a pensar na relação corpo-território na escola. O currículo de resistência se converte em lugar de encontro quando os espaços-tempos são ressignificados pelas demandas mais sensíveis na comunidade escolar, nesse caso um chá de bebê. Quando as alunas demandam a aula de uma professora, é porque houve empatia solidária pelo que nos era caro e comum. Naquele dia, ao invés de mapas, levei fraldas. O que importava para a turma era construir 
novas territorialidades no espaço da sala de aula, sem uma visão heteropatriarcal da gravidez na adolescência.

Afinal, como lembra Zaragocín (2018:7): “colonialidade de gênero define as relações de gênero no lugar". Com os ensinamentos da luta feminista indígena, a autora sugere que o esquecimento do útero é uma violência colonizadora. De fato, a resistência daquela turma em 2008 foi solicitar o espaço da sala de aula para nos lembrar da força do útero. Por essa razão, Zaragocín reivindica que, pela mirada de uma geopolítica feminista decolonial, o útero seja "uma entidade geopolítica" porque garante a continuidade de um grupo. Em outras palavras, nessa perspectiva, o útero é território.

Outra lembrança docente se volta ao meu útero. Importante frisar que é incomum na escrita acadêmica falarmos do nosso corpo, quando sim, como objeto exclusivo da saúde ou do departamento pessoal. Contudo, tendo o compromisso de um ensaio compartición, entendo que estou implicada nesta escrita ao refletir sobre corpo-território.

Um primeiro movimento é falar da relação do meu corpo no espaço escolar. Não tratamos o fato de que nas instituições escolarizadas, ou seja, nas creches, escolas e universidades públicas e privadas, a colonização do espaço é heteropatriarcal, porque não se considera as necessidades especiais e espaciais de um corpo que gera e que demanda novas territorialidades. Toda professora grávida tem histórias para contar de suas gestações na escola.

A escola, por vezes, é um território hostil ao corpo que gera. Escada, salas sem climatização, uma sala dos professores e não das professoras, isto é, sem espaços para o descanso do corpo. Afinal, as cadeiras e mesas são dispostas para o corpo de prontidão. Seis ou até oito horas em pé, em sala ou em deslocamento, enfrentando também uma cidade hostil ao corpo que gera. Sem dúvida, a arquitetura escolar não tem sido acolhedora com qualquer corpo que exija a adaptação do espaço, mas há o silêncio sobre o corpo da professora que aborta.

E quero falar do dia em que abortei, para ensaiar, junto com você, leitor ou leitora, a ideia do corpo-território na direção de um currículo de resistência. Depois de meses de paralisação, o calendário de reposição escolar ou acadêmico é pensado para compensar e comprimir o tempo, desconsiderando nossos corpos. Em outubro de 2012, após a greve, numa quarta-feira, mal tive tempo para almoçar, o deslocamento até a universidade foi, como sempre, num ônibus lotado que me lembrava da precariedade do meu corpo. Ao final da aula, perto das 20 horas, senti fortes cólicas, silenciadas por goles de água e pela interrupção: "seguiremos na próxima semana”. Na quinta pela 
manhã, de volta à universidade, com sangramentos e dores, uma colega me levou à clínica com o útero sem vida.

Quando falamos da geopolítica do útero, a escala do corpo importa para significarmos tempoespaço curricular. Para além das necessárias garantias civis envoltas pela maternidade e pelos direitos trabalhistas, quero chamar atenção para o fato de que a resistência se passa por considerar o útero nas proposições curriculares de resistência. Trata-se ainda de como o útero é considerado na negociação tempo-espaço curricular. O exercício de conceber o corpo-território como argumento curricular, de certo, incorpora uma prática autobiográfica que se abriga no que Miller chamou de "as histórias de nossas circunstâncias atuais" (2014, p. 2049).

Se concordamos com Miller, os registros autobiográficos mapeiam percepções que provocam um fazer curricular. Por isso, inspirada em Taylor, permito-me problematizar como o espaço escolar molda e é moldado pelo corpo (2018: 157), o que me traz à lembrança ser filha de professora e de como eu me territorializava nos espaços de trabalho de minha mãe. Então, imagino que essa memória afete o fato de eu ser professora hoje.

É interessante notar que associo aqui novamente o argumento de Zaragocín. Para ela, há partes do corpo que são mais importantes que outras, em determinados tempos-espaços de morte e violência lenta. Para povos sujeitos ao genocídio, o útero é uma estratégia de enfrentamento contra as lógicas de dominação (2018: 11)5.

Nesse sentido, relaciono a potência da escola em ser ou em se tornar espaço comunitário, por ser um território que permite as múltiplas possibilidades de pertencimento. Inclusive dos homens e das mulheres que, para se relacionarem com a escola, sendo espaço de trabalho e de aprender e ensinar, precisem levar os seus filhos. Não foram poucas as vezes em que fui com minha mãe para seu ambiente de trabalho, onde, nos seus corredores, refeitórios, sala de leitura ou dos professores, me territorializei, estabelecendo um significado de acolhimento naqueles espaços. Anos depois, trabalhei em uma escola onde reencontrei alguns colegas de minha mãe.

\footnotetext{
${ }^{5}$ Lembrando que a geopolítica do útero, de acordo com Zaragocín, não trata da maternidade como obrigatória, mas como uma parte dos corpos em que os povos racializados “enfrentam a lógica de eliminação" (2018:11). E, por sua vez, é a parte do corpo onde pode haver maior autonomia e empoderamento ao se decidir não ter filhos ou interromper a gravidez, enquanto, para outras pessoas com útero, é um lugar de resistência desde a procriação até o empoderamento, ao ser mãe. O encarnamento produzido pelo útero é mais visível nas pessoas transexuais, onde todas as pessoas podem encarnar uma gravidez, não somente a mulher. É assim que não relaciono o útero diretamente às mulheres ou com a maternidade para não cair em essencialismos, inclusive aqueles autodenominados estratégicos ou radicais. Isso forma parte de compreender $\begin{array}{llllll}\text { o útero } & \text { como } & \text { uma } & \text { geopolítica } & (2018: 11) \text {. }\end{array}$
} 
Frequentei aqueles corredores com divergentes e familiares formas de sentir aquela escola. $\mathrm{O}$ que importa nessa lembrança é discutir sobre as muitas possibilidades de se pensar o corpo-território como um argumento conveniente nesses tempos-espaços desafiadores da experiência escolar. Em outras palavras, quero questionar os espaços escolares colonizados que, por diferentes razões, impedem que a minha experiência se repita com outras crianças.

À medida que as escolas produzem lugares de encontro, incluindo as famílias e as demandas da comunidade escolar, a relação corpo-território permite outra gramática espacial, regulando significações que ficam, hoje, violentadas por uma territorialidade que imprime uma lógica de dominação. A precarização das relações do Estado com seus docentes, por vezes, interdita essa possibilidade. Isso porque o professor e a professora se veem obrigados a migrar por diferentes instituições. E são raros, pois, aqueles que iniciam e se aposentam na mesma instituição ou se mantenham lotados exclusivamente numa única escola.

Os laços de pertencimento com a escola passam por como os seus sujeitos produzem diferentes territorialidades, experimentando e produzindo espaços. Dividindo refeições, confessando frustações e partilhando alegrias, a escola, como lugar do encontro, é estratégica para ressignificar propostas curriculares de resistência. Nossa proposta ao compartilhar lembranças e fazer de parte deste texto uma compárticion é expor a impossibilidade de separar o corpo do território. Com isso, nossa intenção é, sobretudo, pensar noutras miradas sobre teorizações e procedimentos em torno do currículo. E, assim como as indígenas feministas, precisamos ocupar e resistir, porque, como exclamou o escritor Geovani Martins, são muitos os que hoje estão "na mira do verme”.

\section{CONSIDERAÇÕES FINAIS}

A morte de uma criança em horário escolar é a morte da escola como lugar seguro, de bemestar. A cidade - em plena anestesia de suas cotidianas perdas - é também impulsionada por suas resistências. Isso porque reinventamos o planejamento coletivo e decidimos oferecer outras propostas curriculares que, por vezes, contrariam um sentido de nacional que se abriga na violência de uma homogeneização. Como toda comunidade escolar, as necropolíticas (as políticas de morte) nos intranquilizam, mas não nos silenciam.

Pensar a aula como espaço e pensar o espaço com a perspectiva pedagógica requer mobilizar o que Inés Dussel e Daniela Gutiérrez chamam de Pedagogia da Mirada: "Uma pedagogia da mirada que aponte a uma relação distinta com a imagem, uma relação não anoréxica, uma relação política e ética mais plena, deveria oferecer outras propostas" (2014:07). 
Logo, o projeto de rever imaginações geográficas de Massey e Zaragocín somado às provocações dos coletivos ecofeministas é encarado aqui como terreno teórico-metodológico que potencializa as análises dos saberes subalternizados, que aparecem com força desestabilizadora nas nossas memórias. Essa afirmação pode ser tomada como pressuposto para desenho teóricometodológico deste ensaio e parece-me uma tática de compartilhar a leitura da potência ética das minhas lembranças de professora, "de sentir na própria pele" a centralidade da relação corpoterritório.

Desse modo, compreendo que a resistência à violência lenta passe pela possibilidade de converter a escola em espaço comum, como lugar de encontro. Tal proposição, ou enfrentamento, é abrir a concepção de currículo, numa via que as ecofeministas nos ensinam como uma nova geopolítica. Isso porque a indissociabilidade corpo-território potencializa a estética como tática na era da censura. Com essa ordem de ideias, pensar o corpo-território repercute numa proposta de um currículo mais democrático. Em outras palavras, se é politicamente estratégico valorizar e repercutir sentidos aprendidos no espaço periférico, dos corpos subalternizados, faz-se necessário questionar o modelo de causa-efeito que flagra uma totalização última do espaço-tempo, silenciando os corpos e os territórios no currículo.

\section{REFERÊNCIAS:}

ACARÓN, Tania. Shape-in(g) space: body, boundaries and violence. Space and Culture 2016, Vol. 19(2) 139-149.

Articulação dos Povos Indígenas do Brasil - APIB. Manifesto “Território: nosso corpo, nosso espírito" Brasília - DF. 12 de agosto de 2019. Disponível em: https://trabalhoindigenista.org.br/documento-final-marcha-das-mulheres-indigenasterritorio-nosso-corpo-nosso-espirito/ Acesso em: agosto de 2019

\section{BUTLER, Judith. Corpos em aliança e política das ruas - notas para uma teoria performativa de assembleia. Civilização Brasileira, Rio de Janeiro, 2018.}

Colectivo Miradas Críticas del Territorio desde el Feminismo, Equador, 2013.

DUSSEL, Inés. \& GUTIÉRREZ, Daniela. Educar la mirada - políticas y pedagogías de la imagen. Ediciones Mananthial, BsAs, 2014, 320p.

GABRIEL, Carmen Teresa. Docência, demanda e conhecimento: articulações em tempo de crise. CURRÍCULO SEM FRONTEIRAS, v. 15, p. 425-444, 2015.

HERNÁNDEZ, Daylma. T. Una mirada muy otra a los territorios-cuerpos femininos. Solar | Año 12, Volumen 12 , Número 1, Lima, pp.35-46.

MACDOWELL, Linda. Unruly bodies and dangerous spaces: Masculinity and the geography of 'dreadful enclosures'. IN: Urban Studies 2019, Vol. 56(2) 419-433. Disponível em: journals.sagepub.com/home/usj. Acesso em maio de 2019. 
MARTINS, Geovani. O sol na cabeça. Companhia das Letras, São Paulo, 2018. MASSEY, Doreen. Space, Place and Gender. Cambridge: Polity Press. 1994.

MASSEY, Doreen. Filosofia e política da espacialidade: algumas considerações. Geographia, 6(12), 2004, p. 07-23.

MASSEY, Doreen. Geographies of responsibility', Geografiska Annaler B 86(1), 5-18, 2004.

MASSEY, Doreen. Pelo espaço. Bertrand do Brasil, 2a . Edição, Rio de Janeiro, 2008.

MBEMBE, Achille. Sair da Grande Noite. Ensaio sobre a África descolonizada. Edições Pedago, Lisboa, 2014, p. 200.

MBEMBE, Achille. Necropolítica. Editora n-1, São Paulo, 2018.

MILLER, Janet. Teorização do currículo como antídoto contra/na cultura da testagem. Revista e-Curriculum, São Paulo, v. 12, n. 03 p. 2043 - 2063 out./dez. 2014.

OLIVEIRA, Denilson. A. Colonialidade, biopolítica e racismo: uma análise das políticas urbanas na cidade do Rio de Janeiro. In: Denilson Araujo de Oliveira; Valter do Carmo Cruz. (Org.). Geografia e o Giro Decolonial: experiências, idéias e horizontes do pensamento crítico. 1ed.Rio de Janeiro: Letra Capital, 2017, v. 1, p. 62-97.

PINAR, William. O que é a Teoria de Currículo?. Porto: Porto Editora, 2007.

TAYLOR, Carol. A. What can bodies do? En/gendering body-space choreographies of stillness, movement and flow in post-16 pedagogic encounters. IN: International Journal of Educational Research. 88 (2018) 156-165. Disponível em: journal homepage: www.elsevier.com/locate/ijedures.

VALVERDE, Clara. De la necropolítica neoliberal a la empatía radical - violência discreta, cuerpos exluídos y repolitizacíon. Icaria Editorial, Barcelona, 133p.

ZARAGOCIN, Sofía. La Geopolítica del Útero: hacia una geopolítica feminista decolonial en espacios de muerte lenta. IN: Cruz, D y Bayon, M. (Eds.), Cuerpos, territorios y feminismos. Quito: AbyaYala y Estudios Ecologistas del Tercer Mundo, 2018. (mimeo) 
Corpo-território como argumento curricular de resistência

resumo

Este texto objetiva narrar as minhas lembranças docentes, com foco na concepção corpo-território como um dispositivo curricular que se alicerça numa interpretação política e estética. Para tanto, procuro fazer com que as geografias feministas (MASSEY, 2004, 2008; ZARAGOCÍn, 2018) conversem com a reflexão curricular. Tais articulações teóricas têm o intuito de potencializar a concepção corpo-território (HERNÁNDEZ, 2016) como ferramenta de teorizações curriculares (MILLER, 2014). A aposta deste texto na relação corpo-território, em especial na geopolítica do útero, está na concepção de um currículo de resistência.

PALAVRAS-CHAVE: Currículo, Corpo-Território.

ABSTRACT

\section{BODY-TERRITORY AS CURRICULAR RESISTANCE ARGUMENT}

This text has as its main purpose to narrate my teaching memories, as the focus on the body-territory conception as a curricular device that is based on a political and aesthetic interpretation. Hence, I look for some dialogues with feminist geographies (MASSEY, 2004, 2008; ZARAGOCÍn, 2018) toward curricular reflection. Such dialogues focus on enhancing the body-territory (HERNÁNDEZ, 2016) conception as a tool for curricular theorizing (MILLER, 2014). The focus of this text on the body-territory relationship, especially on the geopolitics of the uterus, is in the conception of a resistance curriculum.

KEYWORDS: body-territory, curriculum.

CUERPO-TERRITORIO COMO ARGUMENTO CURRICULAR DE RESISTÉNCIA RESUMÉN

Este texto objectiva narrar mis recuerdos de enseñanza, como el enfoque en la concepción del cuerpo-territorio como un dispositivo curricular que se basa en una interpretación política y estética. Con este fin, busco algunos diálogos de geografías feministas (MASSEY, 2004, 2008; ZARAGOCÍN, 2018) para la reflexión curricular. Dichos diálogos se centran en mejorar la concepción del cuerpo-territorio (HERNÁNDEZ, 2016) como una herramienta para la teorización curricular (MILLER, 2014). El enfoque de este texto en la relación cuerpo-territorio, especialmente en la geopolítica del útero, está en la concepción de un currículum de resistencia.

PALABRAS CLAVE: Cuerpo-Territorio, Curriculum.

Submetido em Agosto de 2019

Aprovado em Dezembro de 2019 